\title{
Clinical analysis and study of 844 children with adverse drug reactions in China.
}

\author{
Fuyong Jiao' ${ }^{1}$, Bilal Haider Shamsi2*, Xianpeng Yan $^{1}$, Zhilong Mu${ }^{1}$, Jieying Wang ${ }^{1}$, Xiangyang Guo ${ }^{1}$ \\ ${ }^{1}$ Children's Hospital of Shaanxi Provincial People's Hospital of Xi' an Jiaotong University, Xi'an, PR China \\ ${ }^{2}$ Department of Pediatrics, Shenmu Hospital, Shenmu County, Yulin City, Shaanxi Province, PR China
}

\begin{abstract}
Objective: Retrospective clinical analysis of adverse drug reactions in children. Methods: Clinical data analysis was performed on 844 cases of hospitalized children reported for adverse drug reactions.

Results: Children under 3 y of age were more prone to the adverse drug reactions; adverse reactions were mainly caused by antibiotics and traditional Chinese medicine; intravenous rout was the most common mode of administration of drug causing adverse reaction; adverse drug reaction was mostly observed within $1 \mathrm{~h}$ of drug administration; most common clinical manifestation of adverse drug reactions was the skin damage.

Conclusions: More attention should be paid towards rational use of drugs, to avoid multiple drug use as far as possible, and to focus on prevention of adverse drug reactions, timely detection if happened and immediate treatment. Establishment of drug reaction reporting system will definitely help the physicians across the globe to better understand the phenomenon.
\end{abstract}

Keywords: Adverse drug reactions, Clinical analysis, Children.

Accepted on February 01, 2018

\section{Introduction}

Adverse drug reactions (ADR) are a major health problem to the individual as well as for society [1]. ADR refers to an appreciably harmful or unpleasant reaction, resulting from an intervention related to the use of a medicinal product, which predicts hazard from future administration and warrants prevention or specific treatment, or alteration of the dosage regimen, or withdrawal of the product [2]

With the widespread clinical use of various drugs, irrational use of drugs and misuse is increasing, and alongside the incidence of ADR also increased gradually [3]. ADR monitoring has been unfolding in China, and has caused widespread concern [4].

Study on clinical manifestations caused by ADR, timely reporting, and the analysis of possible causes will improve medical standards and the cure rate, and will decrease mortality and medical care costs.

We retrospectively analyzed 844 cases of adverse drug reactions in hospitalized children for clinical reference and to provide basis for rational drug use.

\section{Methods}

Retrospectively analysis was performed on 844 cases reported for clinical adverse drug reactions in hospitalized children during 2005-2012, including children's gender, age, drugs used, route of administration and major clinical manifestations of ADR.

\section{Results}

\section{Age and gender of children}

There were 477 male cases (56\%) and 367 female cases (44\%) amongst 844 children. male and female ratio was 1.30:1. Amongst all 844 cases, $75 \%$ ADR occurred in infants less than $3 \mathrm{y}$ of age, which is statistically significant $(\mathrm{P}<0.0001)$. ADR cases with respect to all ages are showed in Table 1.

\section{The variety and distribution of drugs in ADR}

There were 56 types of drugs involved in 844 cases of children with ADR, of which statistically significant number $(\mathrm{P}<0.0001)$ of 545 cases were caused by anti-microbial drugs $(65 \%)$, followed by traditional Chinese medicine, respiratory drugs, cardiovascular drugs and nervous system drugs. 
ADR caused by the drug types and number of cases are shown in Table 2.

Table 1. The relationship of age and $A D R$.

\begin{tabular}{|c|c|c|c|c|c|}
\hline Age (y) & Numbers (n) & Percentage (\%) & $\mathbf{P}$ & $\mathrm{X} 2$ & $95 \% \mathrm{Cl}$ \\
\hline$<1$ & 320 & 38 & $P<0.0001$ & 46.679 & 28.3596 to 47.7902 \\
\hline $1 \sim 3$ & 315 & 37 & $P<0.0001$ & 45.172 & 27.4378 to 46.7795 \\
\hline $4 \sim 6$ & 119 & 14 & $P=0.0001$ & 14.978 & 7.3935 to 22.1372 \\
\hline $7 \sim 10$ & 51 & 6 & $P=0.0131$ & 6.155 & 1.0946 to 12.4768 \\
\hline $11 \sim 14$ & 39 & 5 & $P=0.0239$ & 5.103 & 0.3328 to 11.1750 \\
\hline Total & 844 & 100 & & & \\
\hline
\end{tabular}

Campbell Chi-squared test; Altman confidence interval; $\mathrm{P}<0.05=$ Significant.

\section{Route of administration and $A D R$}

735 of 844 cases with ADR were caused by intravenous which was significantly higher $(\mathrm{P}<0.0001)$ than other routes of administration. The route of administration and number of cases are shown in Table 3.

\section{The timeline of ADR symptoms}

There were 356 cases which occurred within 30min after administration, 170 cases in $1 \mathrm{~h}, 146$ cases in $1 \sim 2 \mathrm{~h}, 111$ cases in $2 \sim 6 \mathrm{~h}$, and 61 case after $6 \mathrm{~h}$ respectively Table 4 .

\section{Organs involvement and major clinical manifestations}

ADR effected mainly the skin and its appendages in children $(\mathrm{P}<0.0001)$, followed by the digestive system, nervous system and blood system respectively. Main clinical manifestations were local or systemic rash (such as maculopapular rash and urticarial rash). Table 5 shows the system wise clinical manifestations.

Table 2. The types of drugs and number of cases in children with ADR.

\begin{tabular}{|c|c|c|c|c|c|}
\hline Types of drugs & Number (n) & Percentage (\%) & $\mathbf{P}$ & $\mathbf{x}^{2}$ & $95 \% \mathrm{Cl}$ \\
\hline Anti-microbial drugs & 545 & 65 & $P<0.0001$ & 95.815 & 54.5759 to 73.6358 \\
\hline Traditional Chinese medicine & 169 & 20 & $P<0.0001$ & 22.111 & 12.3787 to 28.8829 \\
\hline Respiratory drugs & 43 & 5 & $P=0.0239$ & 5.103 & 0.3328 to 11.1750 \\
\hline Cardiovascular drugs & 37 & 4 & $P=0.0439$ & 4.061 & -0.4281 to 9.8371 \\
\hline Nervous system drugs & 36 & 4 & $P=0.0439$ & 4.061 & -0.4281 to 9.8371 \\
\hline Others & 14 & 2 & $P=0.1563$ & 2.01 & -1.9733 to 7.0012 \\
\hline Total & 844 & 100 & & & \\
\hline
\end{tabular}

Campbell Chi-squared test; Altman confidence interval; $\mathrm{P}<0.05=$ Significant.

Table 3. The route of administration and number of cases.

\begin{tabular}{|c|c|c|c|c|c|}
\hline Route of administration & Number (n) & Percentage (\%) & $\mathbf{P}$ & $x^{2}$ & $95 \% \mathrm{Cl}$ \\
\hline Intravenous drop infusion & 735 & 87 & $P<0.0001$ & 153.212 & 78.203 to 92.242 \\
\hline Intravenous injection & 39 & 4 & $P=0.0439$ & 4.061 & -0.4281 to 9.8371 \\
\hline Intramuscular injection & 22 & 3 & $P=0.0817$ & 3.03 & -1.1933 to 8.4519 \\
\hline Oral & 43 & 5 & $P=0.0239$ & 5.103 & 0.332 to 11.175 \\
\hline Others & 9 & 1 & $P=0.3173$ & 1 & -2.7898 to 5.4486 \\
\hline Total & 844 & 100 & & & \\
\hline
\end{tabular}


Campbell Chi-squared test; Altman confidence interval; $\mathrm{P}<0.05=$ Significant.

Table 4. The time of ADR and number of cases.

\begin{tabular}{llllll}
\hline Time to ADR symptoms & Number $(\mathbf{n})$ & Percentage $(\%)$ & $\mathbf{P}$ & $\mathbf{X}^{2}$ & $\mathbf{9 5 \%} \mathbf{C l}$ \\
\hline Within $30 \mathrm{~min}$ & 356 & 42 & $\mathrm{P}<0.0001$ & 52.899 & 32.0826 to 51.7935 \\
\hline $\mathrm{In} 1 \mathrm{~h}$ & 170 & 20 & $\mathrm{P}<0.0001$ & 22.111 & 12.3787 to 28.8829 \\
\hline $1 \sim 2 \mathrm{~h}$ & 146 & 18 & $\mathrm{P}<0.0001$ & 19.681 & 10.6944 to 26.6674 \\
\hline $2 \sim 6 \mathrm{~h}$ & 111 & 13 & $\mathrm{P}=0.0002$ & 13.834 & 6.5834 to 20.9804 \\
\hline Beyond $6 \mathrm{~h}$ & 61 & 7 & $\mathrm{P}=0.0072$ & 7.218 & 1.8603 to 13.7495 \\
\hline Total & 844 & 100 & & & \\
\hline
\end{tabular}

Campbell Chi-squared test; Altman confidence interval; $P<0.05=$ Significant.

Table 5. Organs involvement and clinical manifestations in children with ADR.

\begin{tabular}{|c|c|c|c|c|c|c|}
\hline Organs involvement & Clinical manifestations & $N(n)$ & $(\%)$ & $\mathbf{P}$ & $x^{2}$ & $95 \% \mathrm{Cl}$ \\
\hline Skin and its appendages & $\begin{array}{l}\text { Local or systemic rash, skin itching, redness } \\
\text { and swelling and pain at the injection site }\end{array}$ & 733 & 87 & $P<0.0001$ & 153.212 & 78.20 to 92.24 \\
\hline High hepatic aminotransferase & $\begin{array}{l}\text { Nausea, vomiting, abdominal pain, diarrhea, } \\
\text { high aminotransferase }\end{array}$ & 134 & 16 & $P<0.0001$ & 17.304 & 9.032 to 24.420 \\
\hline Nervous system & Irritability, dizziness, headache, drowsiness & 82 & 10 & $P=0.0012$ & 10.474 & 4.1923 to 17.4366 \\
\hline Blood system & Anemia, reduction of granulocytes & 37 & 4 & $P=0.0439$ & 4.061 & -0.4281 to 9.8371 \\
\hline Respiratory system & Tachypnea, dry cough & 23 & 3 & $P=0.0817$ & 3.03 & -1.1933 to 8.4519 \\
\hline Others & Increased heart rate, fever, chills & 62 & 7 & $P=0.0072$ & 7.218 & 1.8603 to 13.7495 \\
\hline
\end{tabular}

Campbell Chi-squared test; Altman confidence interval; $\mathrm{P}<0.05=$ Significant.

\section{Treatment and prognosis}

675 of 844 cases with ADR were given symptomatic treatments. Others didn't need any treatment. If ADR occurred in children; (1) The suspicious drug was stopped, to reduce the amount of toxins; (2) Hydration was ensured to excrete the intravenous drug injected; (3) Drugs were used to protect the liver and kidney, reducing target organ damage; (4) The appropriate corticosteroids were used to reduce ADR severity.

\section{Discussion}

The incidence of ADR in infants of age less than $3 \mathrm{y}$ is $75 \%$ in our study, especially under $1 \mathrm{y}$ of age $(38 \%)$, which is the highest of all age groups. This trend is in agreement of the previous reports [5]. This phenomenon may be related to the growth and development of the baby and breast feeding. In this age group, the physiological functions of body organs are immature and are vulnerable to invasion of pathogenic microorganisms, increasing the chances of medication [6]. At the same time, body's metabolism of the drug is slow, resulting in decreased elimination and increased accumulation of the drugs prone to high reactivity, which causes increased incidence of ADR.
544 of 844 cases in children with ADR were caused by the anti-microbial agents, which is significantly higher $(\mathrm{P}<0.0001)$. Previous reports have also mentioned the ADR phenomenon against antimicrobial agents [7]. Because of a variety of antimicrobial drugs in recent years, particularly cephalosporins, these are consumed in large quantities increasing opportunities for relevant allergens [8]. Also, the irrational drug use, such as a longer than required course of treatment and larger than recommended doses are also increasing the chances of ADR [9]. Clinicians should follow evidence based practice, to reduce the irrational use of antimicrobials, unnecessary combination therapy and frequent change of medicine, during a course of treatment.

The extensive use of antimicrobial drugs produces more resistant strains, and can cause the floral imbalance in children, causing them to suffer from skin rash and antibiotic associated diarrhoea [10,11]. Recent research done in Denmark found that the systemic application of antibiotics and vaccines caused adverse reactions in every 2 out of 3 children below 2 y of age [12]. The rational use of antibiotics must be implemented to reduce or avoid unnecessary drugs, combination therapy, drug overdose, and excessive duration of treatment. If necessary, treatment should be carried out in accordance with blood medicine concentration. 
Traditional Chinese medicine has a long history in China and usually has moderate medicinal function, which has long been considered to be safe and effective with fewer side effects [13]. But with more awareness about traditional Chinese medicine in many countries and traditional Chinese medicine injections used extensively, the reports of Chinese medicine ADR are also increasing [14]. The reason being TCM injections have complex macromolecules and contain a variety of allergens. Therefore, use of traditional Chinese medicine alone or administered with other drugs in combination, can trigger changes in the blood $\mathrm{pH}$ and can significantly increase the incidence of ADR [15]. Meanwhile, processing of raw materials, storage, and preparation of TCM can affect the quality of products, which may trigger allergic reactions. Our study reported TCM to be the second most significant drug responsible for ADR. So strengthening the quality control of TCM injections, improving the skill level of medical staff, and rational use of TCM injections can strengthen the Chinese ADR monitoring and research.

Intravenous drug delivery is a major cause of adverse drug reactions in this study which is in agreement with previous studies [16]. In over $90 \%$ of the reports the drug was administered intravenously. This is because in the intravenous administration, the drug directly enters into the blood, and high plasma concentrations make the bodily systems more prone to adverse reaction [17]. Regarding intravenous infusion administration, medical staff should strictly follow the regulations i.e., to avoid improper liquid compatibility, to ensure correct infusion rate and to reduce unnecessary intravenous administration.

Most ADR in children occurred within $1 \mathrm{~h}$ of the drug administration favouring the previous reports [18]. So we should enhance the first hour observation, to deal with and to avoid serious consequences.

The target damage of ADR in our study was predominantly skin and its appendages, corresponding with previous reports, which may be related to two factors: the early clinical manifestations of skin reactions, and hidden damage to other organs or systems [19].

\section{Conclusion}

ADR can be managed by detailed drug allergy history, avoidance of excessive drugs especially unnecessary IV infusions, strengthening the monitoring of adverse drug reactions by accurate systemic observation, timely reporting and early management accordingly, to reduce its incidence and complications, and to avoid mortality.

\section{References}

1. Bouvy JC, De Bruin ML, Koopmanschap MA. Epidemiology of adverse drug reactions in Europe: a review of recent observational studies. Drug safety 2015; 38: 437-453.
2. Walsh D, Lavan A, Cushen AM. Adverse drug reactions as a cause of admission to a Dublin-based university teaching hospital. Irish J Med Sci 2015; 184: 441-447.

3. Mao W, Vu H, Xie Z. Systematic review on irrational use of medicines in China and Vietnam. PloS One 2015; 10: $\mathrm{e} 0117710$.

4. Singh S. Irrational use of antimicrobial agents. Int J Med Dental Sci 2018; 2: 1-2.

5. Bellis JR, Kirkham JJ, Nunn AJ. Adverse drug reactions and off-label and unlicensed medicines in children: a prospective cohort study of unplanned admissions to a paediatric hospital. Brit J Clin Pharmacol 2014; 77: 545-553.

6. Simon AK, Hollander GA, McMichael A. Evolution of the immune system in humans from infancy to old age. Proc Biol Sci 2015.

7. Jayanthi C, Chaithra K, Reddy SN. A profile of adverse drug reactions to antimicrobial agents at a tertiary care hospital. Indian J Pharm Pharmacol 2017; 4: 16-21.

8. De Simone B, Catena F, Sartelli M. Common errors in the treatment of intra-abdominal infections: the irrational use of antimicrobial agents. Emerg Care J 2016; 12: 2.

9. Hameed A, Naveed S, Qamar F. Irrational use of antibiotics. Different Age Groups of Karachi: A Wakeup Call for Antibiotic Resistance and Future Infections. J Bioequiv Availab 2016; 8: 242-245.

10. Pfützner W, Rose M, Nilles N. Drug-induced skin reaction elicited by clindamycin and penicillin: one rash, but two culprits. Clin Trans Allergy 2014; 4: 139.

11. McFarland LV, Ozen M, Dinleyici EC. Comparison of pediatric and adult antibiotic-associated diarrhea and Clostridium difficile infections. World J Gastroenterol 2016; 22: 3078 .

12. Aagaard L, Weber CB, Hansen EH. Adverse drug reactions in the paediatric population in Denmark. Drug safety 2010; 33: 327-339.

13. Tang H, Huang W, Ma J. SWOT analysis and revelation in traditional Chinese medicine internationalization. Chin Med 2018; 13: 5.

14. Xutian S, Junion J, Wozniak L. New exploration and understanding of traditional Chinese medicine, in handbook of traditional Chinese medicine. World Scientific 2015; 139-154.

15. Teschke R, Zhang L, Long H. Traditional Chinese medicine and herbal hepatotoxicity: a tabular compilation of reported cases. Ann Hepatol 2015; 14: 1.

16. Dorman SM, Seth S, Khan DA. Risk of allergic reactions to recurrent intravenous penicillin administration in penicillin skin test negative patients. J Allergy Clin Immunol 2018; 6: 196-200.

17. Wang C, Graham DJ, Kane RC. Comparative risk of anaphylactic reactions associated with intravenous iron products. JAMA 2015; 314: 2062-2068.

18. Mendes Marques JIO, Polónia JMJ, Figueiras AG. Nurses' attitudes and spontaneous adverse drug reaction reporting: a 
case-control study in Portugal. J Nursing Management 2016; 24: 409-416.

19. Aronson JK. Meyler's side effects of drugs: the international encyclopaedia of adverse drug reactions and interactions. Elsevier 2015.

\section{*Correspondence to}

Bilal Haider Shamsi

Department of Pediatrics

Shenmu Hospital

Shenmu County

Yulin City

Shaanxi Province

PR China 